\title{
Transparência em DADOS: submissões, pareceristas e diversidade no fluxo editorial dos últimos anos ${ }^{*}$
}

\author{
Luiz Augusto Campos ${ }^{1}$ \\ ${ }^{1}$ Editor-Chefe de DADOS e Professor de Sociologia e Ciência Política do Instituto de Estudos Sociais e \\ Políticos da Universidade do Estado do Rio de Janeiro (IESP-UERJ), Rio de Janeiro, RJ, Brasil \\ E-mail: lascampos@iesp.uer..br \\ Marcia Rangel Candido ${ }^{2}$ \\ ${ }^{2}$ Editora-Assistente de DADOS e Doutora em Ciência Política pelo Instituto de Estudos Sociais e Políticos \\ da Universidade do Estado do Rio de Janeiro (IESP-UERJ), Rio de Janeiro, RJ, Brasil \\ E-mail: marciacandido@iesp.uerj.br
}

\section{INTRODUÇÃO}

\begin{abstract}
editoração acadêmica vive desafios no mínimo paradoxais. De um A lado, nunca se exigiu tanta celeridade, confiabilidade, transparência e publicidade da comunicação de pesquisas quanto em meio à atual pandemia da Covid-19 - momento no qual as publicações científicas podem literalmente ajudar a salvar vidas. Curiosamente, a acentuação dessas demandas ocorre em simultâneo a transformações estruturais no modo como se comunica a ciência, iniciadas poucas décadas atrás e relacionadas à abertura e transparência dos processos de investigação - ou ao que se convencionou chamar de programa da ciência aberta. Por outro lado, raros foram os momentos históricos em que a ciência sofreu tantos ataques, quase sempre orquestrados por coalizões política ou economicamente interessadas em seu fracasso e censura. Aqui não estamos falando apenas de opiniões ou ideologias negacionistas, mas sobretudo das restrições financeiras que, em continuidade com essas visões, corroem a pesquisa acadêmica no mundo e especialmente no Brasil.
\end{abstract}

\footnotetext{
*Gostaríamos de agradecer nominalmente ao conselho de redação da revista por sugestões e revisões a este editorial: Breno Bringel, Carlos Antonio Costa Ribeiro, Charles Pessanha, Fernando Guarnieri e Letícia Pinheiro. Grande parte dos dados utilizados foram gerados pela nossa equipe editorial, composta por Marina Bezerra, Murilo Gomes Costa, Matheus Pestana e Marcia Rangel Candido. Por fim, agradecemos a Marcos Campos pelo trabalho de codificação dos pareceres anônimos utilizados em uma das seções e a Jun Shimada pela revisão e tradução do manuscrito.
}

DADOS, Rio de Janeiro, vol.65 (1): e20220000, 2022

https://doi.org/10.1590/dados.2022.65.1.000 
Esses desafios não foram inaugurados pela pandemia. Anos antes, em 2017, DADOS foi particularmente afetada pelos cortes das fontes de fomento fluminenses, seguidos pela decretação do estado de calamidade pública no Rio de Janeiro. Um contexto que já não era positivo aos periódicos científicos levou rapidamente à dissolução quase completa de nossa equipe editorial e de nossas tradicionais fontes de financiamento. Não é exagero dizer que a revista, que acabava de completar 50 anos de existência, esteve prestes a fechar.

Ainda que a conjuntura adversa só tenha se agravado desde então, $D A D O S$ conseguiu reestruturar sua equipe e recompor fontes mínimas para seu sustento, tudo isso com o apoio do Instituto de Estudos Sociais e Políticos (IESP), da Universidade do Estado do Rio de Janeiro (UERJ), e de toda a comunidade científica. Não apenas colocamos em dia o fluxo de artigos e atualizamos nossa política editorial para conferir maior confiabilidade e celeridade aos processos de avaliação, mas também começamos a incorporar boas práticas do programa da ciência aberta, que constitui um conjunto de transformações radicais das práticas de editoração.

Neste editorial, discutimos os resultados de tais esforços, bem como as dificuldades que ainda permanecem. Apresentamos aqui uma análise cienciométrica de diversas dimensões do fluxo da $D A D O S$ que vai das submissões recebidas pela revista ao perfil de seus pareceres e pareceristas, passando pelas desigualdades de gênero e de origem geográfica que ainda persistem nesses âmbitos. Pretendemos assim garantir a mais ampla transparência dos nossos processos editoriais, sem prejudicar, contudo, os critérios de discrição que embasam o sistema de revisão anônima por pares. O nosso intuito é acima de tudo compartilhar as estratégias que utilizamos para contornar os obstáculos interpostos, na expectativa de que elas possam servir como instrumentos de resistência para outros periódicos científicos. Além disso, almejamos informar o restante da comunidade sobre a responsabilidade coletiva que nos une - seja entre os que cuidam das esferas de divulgação científica, seja entre os que precisam desses meios para circular seus trabalhos.

O texto está dividido em quatro seções. Na primeira, apresentamos informações gerais sobre nosso fluxo editorial - o que engloba o tempo médio de avaliação dos manuscritos, suas taxas de aceitação e recusa. Na segunda, por sua vez, apresentamos uma análise de conteúdo iné- 
dita sobre os pareceres recebidos pela revista, o perfil de nossos avaliadores e as razões de recusa por eles mencionadas. Na sequência, tratamos do perfil de gênero e de origem geográfica de nossa comunidade de autores(as) e pareceristas, ponderando os efeitos desiguais da pandemia da Covid-19 na participação de homens e mulheres nessas atividades, bem como a variação da procedência nacional. Por fim, na quarta e última seção, expomos as iniciativas que temos mobilizado para modernizar, manter e expandir a qualidade e a visibilidade dos números da DADOS.

Não existe ciência sem comunicação científica, e ela ainda depende sobremaneira dos periódicos acadêmicos. Por mais fria e técnica que uma política editorial possa parecer, ela sempre busca induzir determinados padrões de rigor científico, influenciando uma determinada forma de se fazer, comunicar e debater a pesquisa. Portanto, analisar os mecanismos, as dificuldades e as transformações de nosso fluxo e de nossa política editoriais é refletir acerca do seu papel na indução de determinados campos científicos. Assim esperamos contribuir para o aprofundamento da reflexão em torno da editoração científica a partir das Ciências Sociais praticadas no contexto nacional.

\section{SUBMISSÕES}

Há algumas características que singularizam $D A D O S$ em comparação a outras publicações periódicas das Ciências Sociais nacionais. Fundada em 1966, a revista é uma das mais antigas dessa grande área no país e uma das primeiras a incorporar o sistema de revisão por pares ainda na década de 1970. DADOS também foi a primeira de seu escopo a fazer parte da Plataforma SciELO em 1996, e é um dos poucos periódicos da coleção que editam quatro números ao ano. A revista é indexada em diversas bases nacionais e internacionais, com destaque para a plataforma Web of Science. Por conta desses e de outros fatores, é alto o montante de submissões recebidas. Em média, computamos cerca de 270 artigos por ano, o que significa quase um por dia. O Gráfico 1 demonstra, no entanto, a oscilação da quantidade mensal de textos submetidos entre abril de 2015 e abril de 2021: 


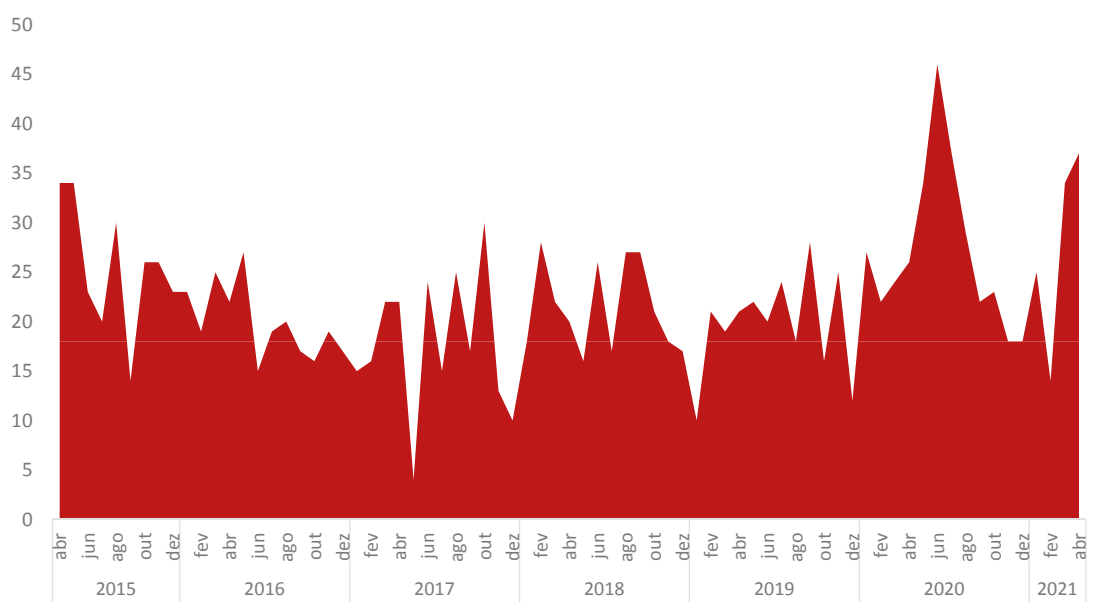

Fonte: ScholarOne. Elaboração própria.

Dois períodos se destacam no Gráfico 1. O primeiro, que abrange o interstício entre 2015 e meados de 2017, acompanha uma queda nas submissões totais, encontrando seu ponto mais baixo em maio de 2017. Tal tendência não foi fortuita: esse é justamente o momento mais agudo da crise no estado do Rio de Janeiro e dos seus reflexos em nossa editoria. Desde 2019, porém, há um aumento paulatino nas submissões, com um recorde em junho de 2020. Esse pico se deveu não apenas à reestruturação de nossa equipe e de financiamentos, mas também a um efeito não intencional da pandemia de Covid-19, que levou à suspensão de várias atividades acadêmicas no mundo e a um consequente aumento da submissão de manuscritos (Else, 2020). A partir disso, a maioria dos acadêmicos começou a ter uma nova rotina profissional, orientada pelas políticas de isolamento social e pelo fechamento das universidades às atividades presenciais. Isso levou a um incremento inicial nas submissões, que, no entanto, foi marcado por fortes desigualdades de gênero, como veremos mais à frente.

Os manuscritos submetidos à $D A D O S$ passam por diversos filtros. Em uma primeira etapa, chamada avaliação de desk revieww, eles são avaliados de acordo com sua forma, estilo e adequação às normas da revista. Caso vençam tal etapa, são encaminhados para a análise do conselho de redação, composto pelos editores associados, que fazem uma avaliação mais profunda de seu mérito e sua pertinência ao escopo editorial da revista e indicam pareceristas anônimos para os casos aprovados. Com 
base nas recomendações dos pareceristas, a editoria faz sua decisão final em uma quarta etapa. O Gráfico 2 apresenta os percentuais de textos recusados em cada uma dessas etapas entre 2015 e 2020.

Gráfico 2: Taxas de recusa em cada uma das etapas do fluxo editorial (2015-2020)

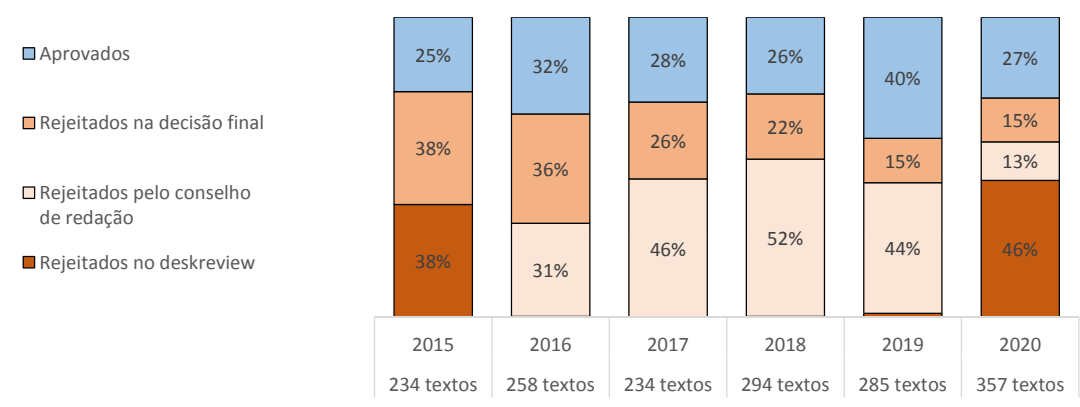

Fonte: ScholarOne. Elaboração própria.

Em consonância com as médias internacionais para as Ciências Sociais (Eberley, Warner, 1990; Hargens, 1988; Weller, 2001; Zuckerman, Merton, 1971), DADOS tem uma taxa de rejeição global que girou em torno de $70 \%$ no período considerado. O primeiro filtro (desk review) é atualmente o mais relevante, eliminando ou retornando aos autores cerca de $46 \%$ dos textos submetidos em 2020. Vale notar que, no período de crise institucional, perdemos o assistente profissionalizado que cumpria tal função, o que sobrecarregou nosso conselho de redação. O montante de textos cuja rejeição se dá depois dos pareceres também não é ignorável, girando em torno de 25\%. Finalmente, 30\% dos textos foram, em média, aprovados para publicação entre 2015 e 2020 - sendo que em 2020 esse percentual foi de $27 \%$. Como veremos na próxima seção, DADOS costuma decidir em consonância com as recomendações dos pareceristas, mas há uma tendência editorial a adotar decisões levemente mais duras que as sugeridas.

O Gráfico 3 apresenta o cálculo do tempo médio em dias corridos entre a submissão de um manuscrito e a primeira decisão editorial ${ }^{1}$ em cada um dos semestres entre 2017 e 2020 . Como é possível perceber, a crise financeira da revista aumentou substantivamente esse tempo entre o primeiro semestre de 2017 e o primeiro semestre de 2019, quando atingimos a marca de 624 dias em média. Esse foi o período de recomposição de nossa equipe, que se dedicou nos meses subsequentes a um mutirão para desafogar o fluxo e recompor a relação com os autores e pareceristas - o que teve impactos consistentes na queda do tempo médio de tramitação. 
Já no segundo semestre de 2019, ele caiu para 421 dias, retomando o patamar do início de 2017. No segundo semestre de 2020, mesmo lidando com um pico de submissões, como visto no Gráfico 1 , atingimos nosso menor período entre submissão e primeira decisão, que foi de 116 dias em média, abaixo da média de 200 dias recomendada pela SciELO.

\section{Gráfico 3: Tempo médio (em dias) de avaliação dos manuscritos submetidos à revista DADOS (2017-2020)}

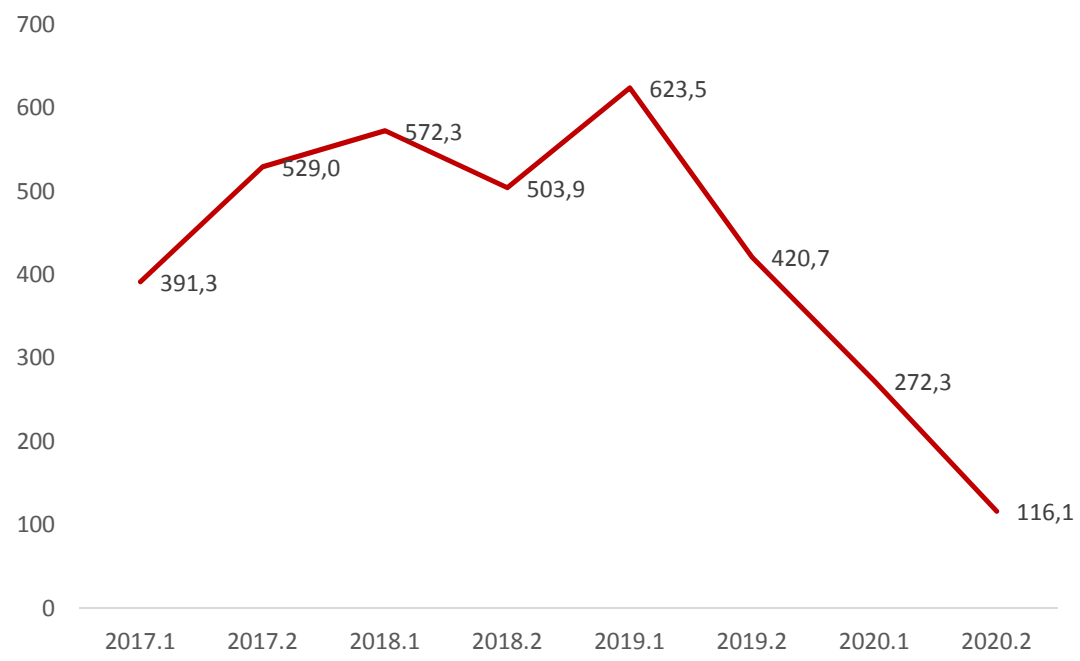

Fonte: ScholarOne. Elaboração própria.

Isso reflete algumas mudanças da nossa política editorial. Em primeiro lugar, estabelecemos regras mais claras e um prazo máximo de 30 dias para recusa do texto no desk review. Em segundo lugar, delimitamos normas rígidas sobre o formato dos artigos, como elementos básicos do resumo, o tamanho do título e parâmetros de formatação. O Gráfico 4 apresenta o mesmo dado, só que agregando o tempo entre submissão e primeira decisão por ano em diagrama de caixa. Como é possível perceber, a elevação da média em 2019 foi mais impactada pela multiplicação de outliers, isto é, por artigos que aguardaram muito tempo pela primeira avaliação. Embora tenhamos reduzido sensivelmente esse tempo médio de avaliação, alguns artigos ainda esperam muito pela primeira decisão.

Se essas mudanças aceleraram sobretudo o primeiro filtro dos manuscritos, restava ainda acelerar o processo de revisão por pares. Por envolver terceiros, essa fase não depende totalmente do empenho da equipe editorial da revista. Não custa lembrar que os(as) pareceris- 
tas desempenham um trabalho completamente gratuito e anônimo, o que reduz bastante os incentivos para sua execução. No entanto, para facilitar a avaliação nessa etapa, remodelamos o formulário a ser preenchido pelos pareceristas, agregando a ele um questionário simples com os elementos valorizados pela revista, acompanhado de um breve manual com os princípios que devem nortear a avaliação (Campos, 2019). Na seção a seguir, exploramos mais os efeitos dessa mudança na revisão por pares.

Gráfico 4: Diagrama de caixa do tempo de avaliação dos manuscritos submetidos à revista $D A D O S$ por ano (2017-2020)

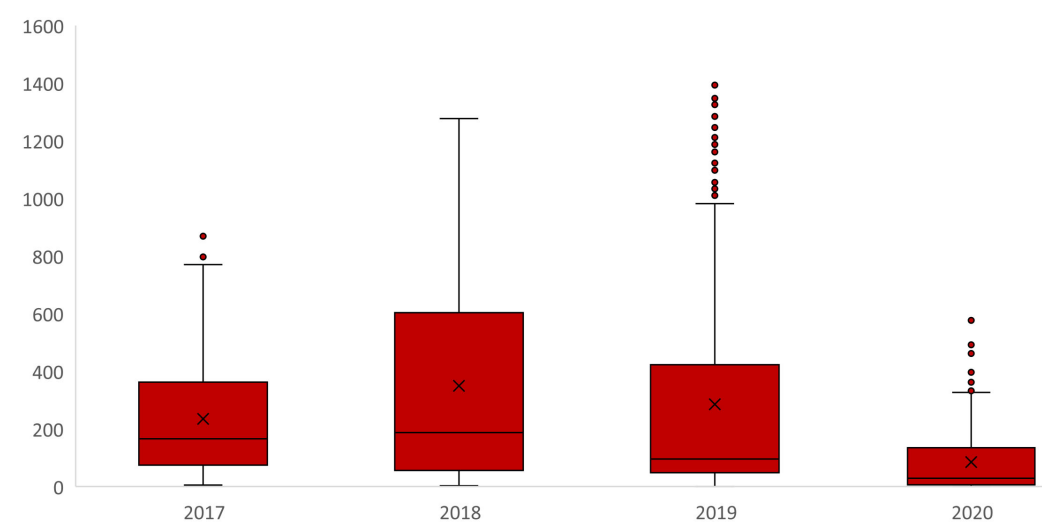

Fonte: ScholarOne. Elaboração própria.

\section{PARECERES}

A despeito de todas as transformações na editoração científica, seu cerne continua sendo a avaliação por pares. Ao contrário do que pode parecer, mesmo os sistemas de avaliação acadêmica aberta, baseados em servidores preprints, ${ }^{2}$ não prescindem do trabalho de pareceristas, seja porque os comentários feitos a manuscritos abertos conformam uma modalidade de parecer, seja porque uma parte considerável desses manuscritos permanece sendo submetida à avaliação por pares (Bohlin, 2004). Um efeito da pandemia da Covid-19 foi ter deixado explícito que, não obstante a importância da divulgação prévia em servidores de preprints, artigos acadêmicos não revisados por pares devem ser lidos com especial cautela.

Ainda assim, não existe consenso sobre a confiabilidade do sistema de revisão cega por pares. Apesar de existir há mais de três séculos, ele só foi disseminado no mundo depois da II Guerra Mundial. Desde então, poucas pesquisas sistemáticas e amplas foram empreendidas acerca 
do tema. Mesmo numerosa, a literatura científica disponível se baseia em estudos de caso limitados a um grupo selecionado de revistas. Isso é explicado pelo fato de que o modelo dominante de avaliação científica se baseia não apenas no anonimato dos(as) pareceristas, mas no segredo de suas avaliações, as quais são acessadas apenas pelos(as) autores(as) envolvidos(as) e pela equipe editorial (Bornmann, 2011).

Com o intuito de contribuir para a reflexão sobre esse sistema, apresentamos a seguir algumas informações quantitativas sobre os pareceres concedidos à $D A D O S$. Como ainda tramitam na revista textos submetidos em 2020, optamos por analisar apenas os pareceres sobre textos submetidos em 2019. Logo, todos os pareceres concedidos foram feitos no sistema duplo-cego, em que nem autores(as), nem pareceristas conhecem as identidades das pessoas envolvidas. No total, DADOS recebeu 366 pareceres redigidos por 262 nomes diferentes, que nos ajudaram a avaliar um total de 173 manuscritos que chegaram a essa fase de tramitação em 2019. Desses 366 pareceres, 26\% recomendaram a aceitação do manuscrito avaliado, $26 \%$ recomendaram pequenas revisões, $20 \%$ grandes revisões, $12 \%$ rejeição com recomendação de ressubmissão e $28 \%$ a rejeição. O gráfico a seguir mostra esses dados e a decisão editorial que se seguiu a cada parecer.

Gráfico 5: Distribuição dos pareceres conforme recomendação do(a) parecerista e decisão editorial (2019)

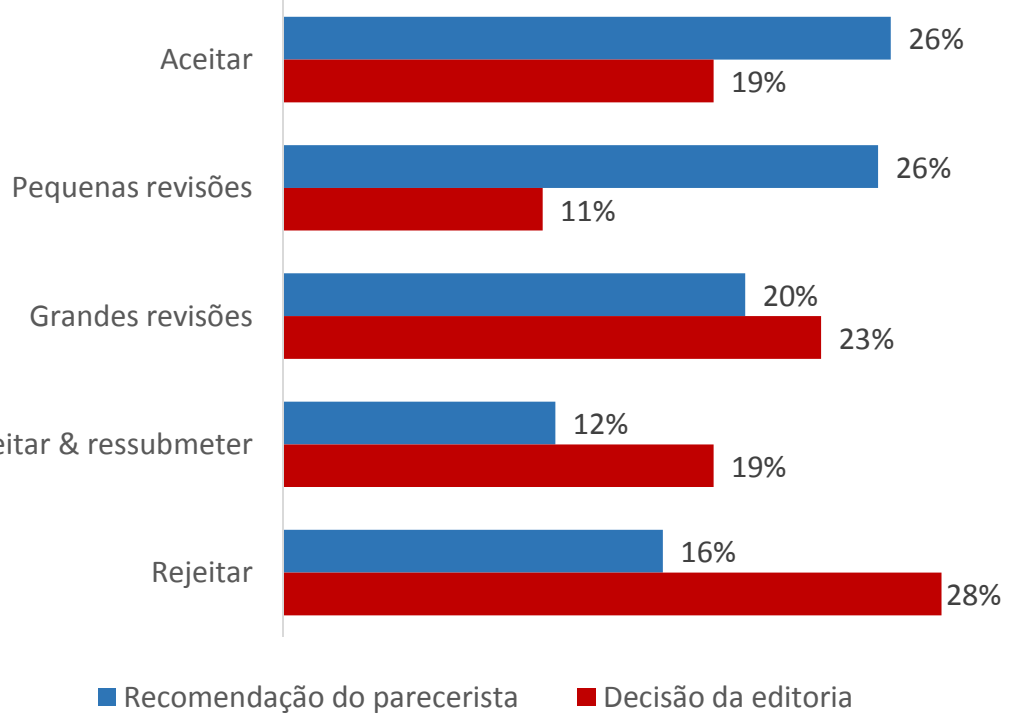

Fonte: ScholarOne. Elaboração própria.

Nota: $\mathrm{N}=173$ manuscritos avaliados por pareceristas. 
Como os dados mostram, as decisões editoriais costumam acompanhar as recomendações dos pareceres - em consonância, aliás, com vários estudos (Bornmann, Daniel, 2010). Em DADOS, as decisões editoriais tendem a ser levemente mais duras do que as recomendações dos pareceristas, haja vista que os percentuais de aceitação são menores na editoria do que nas avaliações dos pares, e que os percentuais de rejeição são maiores. Em $48 \%$ das avaliações, a editoria seguiu à risca a recomendação dos pareceristas, e em $32 \%$ ela optou por uma deliberação próxima - por exemplo, quando o parecer recomenda "pequenas revisões" e a editoria decide por deliberações adjacentes, como "aceitar" ou "grandes revisões". Em 21\% dos casos, a editoria não acatou algum dos pareceres enviados, optando por uma decisão distante da recomendação.

Dos 173 manuscritos recebidos ou ressubmetidos no período, $62 \%$ foram aprovados ou reprovados pela editoria com base em dois pareceres, $23 \%$ demandaram três ou mais pareceres, enquanto $15 \%$ foram decididos com apenas um parecer - casos de ressubmissões de textos previamente aprovados, mas com pequenas revisões. Note-se, contudo, que o número de convites enviados aos pareceristas foi de 545, um montante bastante superior aos 366 efetivamente concedidos. Afora problemas técnicos nos contatos com pareceristas, como cadastros ou endereços de e-mail desatualizados, essa distância entre convites feitos e efetivamente aceitos mostra um problema crônico do sistema de revisão por pares.

Um dos pressupostos implícitos do sistema de revisão por pares é que os pareceres sejam similares no julgamento dos textos avaliados. Daí decorre a premissa de que sempre devemos exigir no mínimo duas avaliações por texto. Para medir a convergência dos pareceres recebidos por um manuscrito, a bibliografia especializada costuma utilizar dois Índices: o coeficiente Kappa de Cohen ou o Índice de Convergência Intraclasses (ICC) (Bornmann, 2011). Em ambos, estima-se o grau de concordância entre dois ou mais avaliadores, descontando-se, contudo, as eventuais concordâncias fortuitas, devidas ao acaso. Apesar das diferenças de cálculo, os dois possuem a mesma métrica: valores mais próximos de 1 indicam alta confiabilidade, e valores próximos de 0 , baixa confiabilidade. 
No entanto, não há consenso nem metodológico nem substantivo quanto ao valor desses índices como meios de mensuração da confiabilidade do sistema. Primeiro, porque os coeficientes foram pensados para testar a confiabilidade de múltiplos julgamentos de juízes comuns - o que não acontece no sistema de revisão por pares, em que cada manuscrito é avaliado por pareceristas distintos (Hargens, Herting, 1990). Segundo, porque os pareceres não definem o destino dos manuscritos nos sistemas de avaliação, mas apenas fornecem subsídios para a decisão final. Assim, alguns especialistas consideram a divergência entre eles um modo salutar de enriquecer as deliberações editorais (Bornmann, 2011:208) e não um índice de baixa confiabilidade do sistema como um todo. Justamente por isso, tanto o Kappa quanto o ICC costumam indicar baixas taxas de concordância para as mais diferentes disciplinas. Em um levantamento sistemático da literatura sobre convergência entre pareceristas, Bornmann (2011:207) mostra que os coeficientes das revistas de diversas áreas são menores do que 0,4 e variam de forma substantiva.

Tabela 1: Convergência entre pareceristas reportada por diferentes estudos

\begin{tabular}{lc}
\hline Periódicos científicos & Kappa/ICC \\
\hline Social Problems & 0,40 \\
Journal of Educational Psychology & 0,34 \\
British Medical Journal & 0,31 \\
American Sociological Review & 0,28 \\
Physiological Zoology & 0,28 \\
Journal of Personality and Social Psychology & 0,26 \\
New England Journal of Medicine & 0,26 \\
Law \& Society Review & 0,17 \\
Angewandte Chemie International Edition & 0,15 \\
Angewandte Chemie & 0,14 \\
Physical Therapy & 0,12 \\
\hline Fonte: Bornmann (2011·207)
\end{tabular}

Por todos esses motivos, decidimos calcular o Kappa de Cohen entre os julgamentos dos dois primeiros revisores dos manuscritos aqui analisados apenas como ilustração, excluindo aqueles ressubmetidos 
que receberam apenas um parecer. Para simplificar o cálculo, fundimos as cinco avaliações possíveis em apenas duas: recomendação de publicação (aceitar + pequenas revisões) e recomendação de não publicação (grandes revisões + rejeitar e ressubmeter + rejeitar). $\mathrm{O}$ resultado geral foi 0,42 - número superior aos estudos mencionados na tabela acima.

Esses estudos quantitativos sobre os pareceres costumam ignorar uma das dimensões mais importantes deles: o conteúdo. A principal função dos pareceres é indicar problemas presentes nos manuscritos submetidos, não apenas para determinar sua rejeição ou publicação, mas também para melhorá-los. Nesse sentido, eles são instrumentos centrais de uma editoração científica compreendida como um modo de induzir a melhora de determinados campos científicos. Por isso, uma questão relevante se relaciona aos equívocos mais recorrentemente apontados nos textos que atingem certa qualidade, pois já passaram pelos filtros iniciais do processo de avaliação. Para investigar quais as falhas indicadas com mais frequência por pareceristas no trabalho de cientistas, fizemos uma categorização das principais críticas presentes nos pareceres, chegando às 15 categorias expostas abaixo. Como é possível verificar no Gráfico 6, a maioria dos pareceres aponta problemas na metodologia dos manuscritos submetidos (38\%). Em segundo lugar vêm os problemas no estilo e na clareza da escrita (33\%). Em seguida vêm as críticas à revisão bibliográfica (27\%), à ausência de contribuição original (23\%) e aos limites dos dados empíricos mobilizados $(20 \%)$. 
Gráfico 6: Objeto de crítica dos pareceres (2019)

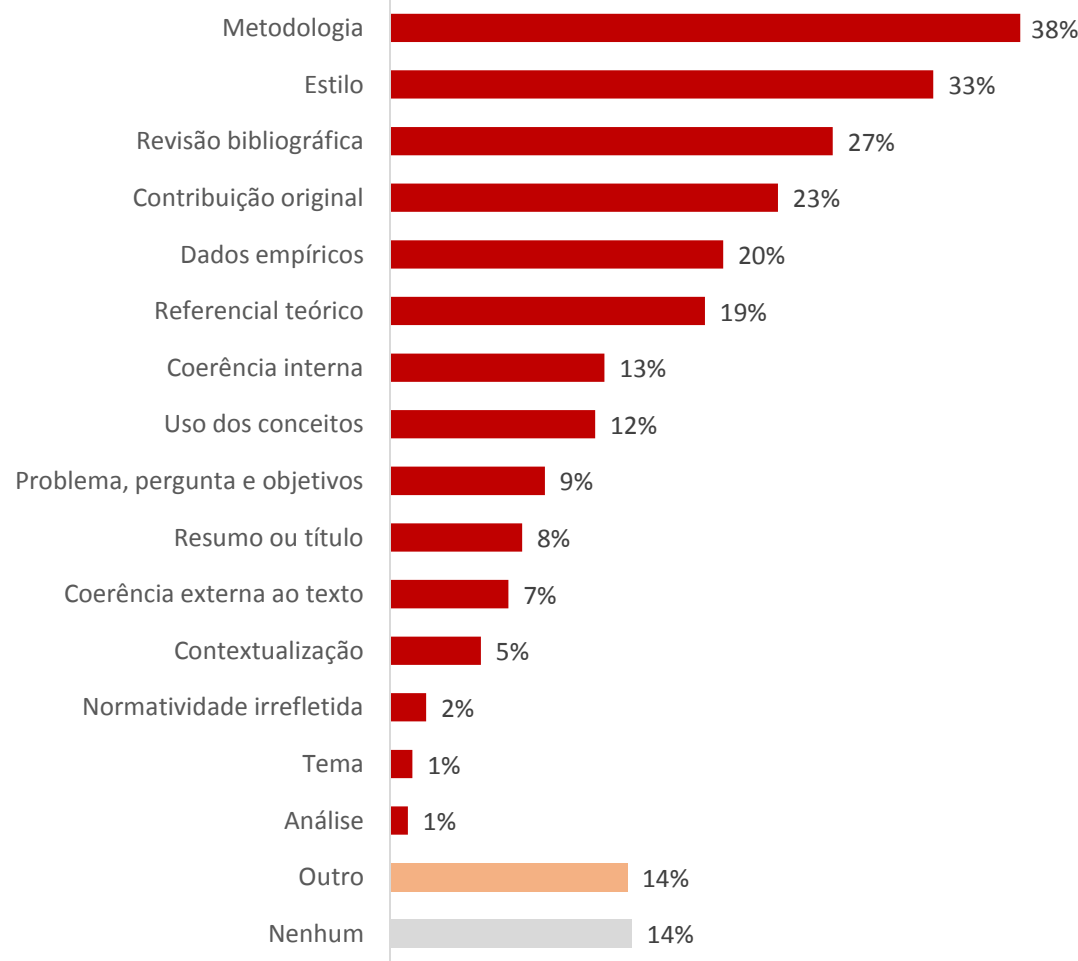

Fonte: ScholarOne. Elaboração própria.

Nota: $\mathrm{N}=366$ pareceres

Os dados do gráfico acima mostram as principais insuficiências dos textos submetidos e sua relação com o trabalho editorial da revista. Uma análise preliminar de anos anteriores indicou que o problema mais recorrente apontado por pareceristas residia na falta de uma contribuição original, o que levou a revista a incluir questões sobre isso tanto no formulário de submissão quanto no de avaliação. Como resultado, houve uma redução dessas críticas, que em 2019 corresponderam à quarta posição. No entanto, aspectos metodológicos ainda suscitam muitas reações negativas dos pareceristas, o que reflete diferentes fatores. Primeiro, a própria história de DADOS está tradicionalmente ligada à publicação de artigos com contribuições metodológicas. Segundo, em concordância com o que Glaucio Ary Dillon Soares chamou de calcanhar de Aquiles da formação brasileira em Ciências Sociais, falta rigor no uso de metodologias quantitativas, e, especialmente, qualitativas (Soares, 2005). 
Por acreditarmos na missão indutora da editoração científica, DADOS vem envidando esforços para garantir a qualidade metodológica de seus artigos, seja a partir da convocação de pareceristas especialistas nos métodos empregados pelos manuscritos avaliados, seja pela adesão à política de replicabilidade de análises. Desde 2020, a revista exige a indexação das bases de dados e os scripts de programação utilizados nos textos, com ênfase em informações quantitativas, mas também inclui dados qualitativos, como documentos, transcrições completas de entrevistas, imagens etc. Esperamos assim incorporar as boas práticas mais atuais da ciência aberta, além de consolidar o foco do periódico na publicação de pesquisas metodologicamente rigorosas e com contribuições originais à academia e ao debate público mais amplo.

\section{DIVERSIDADE}

As desigualdades nas Ciências Sociais variam de disciplina para disciplina. Dados sobre o Brasil mostram a Antropologia como o campo mais feminizado, seguido de uma relativa paridade de gênero na Sociologia e um predomínio de homens na Ciência Política (Carpiuc, 2016; Candido, Feres Júnior, Campos, 2019; Feres Júnior, 2020). No caso da última, pesquisas em distintos países do mundo já evidenciaram e tentaram explicar o fenômeno da sub-representação do gênero feminino na autoria de artigos e livros. ${ }^{3}$ Algumas das causas sugeridas são a baixa abertura das revistas a temáticas e metodologias nas quais as mulheres se destacam - como os próprios estudos de gênero -, o menor fluxo de submissões assinadas pelo grupo, os impedimentos específicos de evolução na carreira em função da sobrecarga com os trabalhos de cuidado, a aversão ao risco de rejeição e o maior grau de autoexigência sobre seus próprios feitos (Djupe, Smith, Solhey, 2018; Brown et al., 2019; Samuels, Teele, 2018).

Durante a pandemia de Covid-19, a sub-representação de mulheres na autoria de artigos ganhou um novo ciclo de estudos, os quais buscaram dimensionar os impactos do trabalho remoto sobre as desigualdades já existentes na esfera privada. No Brasil, ganhou proeminência a questão da maternidade no levantamento do movimento Parent in Science, que, sem distinguir campos disciplinares, demonstrou que a produtividade acadêmica de mulheres negras e de mulheres brancas com filhos foi a mais afetada pela crise (Staniscuaski et. al., 2021). Em diálogo com essas pesquisas, autoras também pontuaram 
os riscos de restringir análises de sobrecarga de mulheres apenas ao âmbito da maternidade, visto que são elas que acumulam tarefas não remuneradas, domésticas e de cuidado mesmo quando não são mães (Castro, Chaguri, 2020).

Cui, Ding e Zhu (2020), por sua vez, analisaram 41.858 papers de diferentes países no maior repositório de preprints das Ciências Sociais e constataram um aumento das disparidades entre homens e mulheres em tais publicações. Além disso, eles chamaram a atenção a importantes distinções entre as áreas do conhecimento examinadas, o que pode implicar limitações a generalizações sobre a produção científica. A Antropologia, por exemplo, teve queda geral de envio de manuscritos, enquanto a Ciência Política teve crescimento - permeado, entretanto, pelo incremento da desigualdade de gênero entre os autores. Pesquisas no Brasil também indicaram variações de impacto da pandemia, tanto em relação a gênero e raça dos(as) pesquisadores(as), como entre disciplinas de trabalho nas Ciências Sociais, com a Antropologia sendo mais penalizada em termos de impedimentos para desenvolver métodos como etnografia, observação participante etc. (Candido et al., 2021).

Para verificar possíveis consequências da pandemia nas desigualdades de gênero em $D A D O S$, nós extraímos a identificação da autoria e imputamos sexo a partir de um pacote no $R$, que se baseia em informações do Instituto Brasileiro de Geografia e Estatística (IBGE). ${ }^{4}$ Os nomes remanescentes, não reconhecidos após rodarmos o programa, foram computados manualmente. Os resultados (Gráfico 7) evidenciaram que o pico de submissões no segundo semestre de 2020 foi eminentemente causado por textos cuja primeira autoria era masculina. No que toca às diferenças entre as Ciências Sociais, o auge de textos recebidos no período pode ter relação também com a vocação temática de nossa revista, que usualmente publica mais artigos de Ciência Política e Sociologia (Campos, Feres Júnior, Guarnieri, 2017), e não tanto de Antropologia, área que parece ter, comparativamente, sido mais afetada pelas mudanças drásticas de socialização durante a crise inicial do novo coronavírus (Cui, Ding, Zhu, 2020; Candido et al., 2021). 
Gráfico 7: Quantidade de submissões por gênero da liderança da autoria e trimestre (2017-2020)

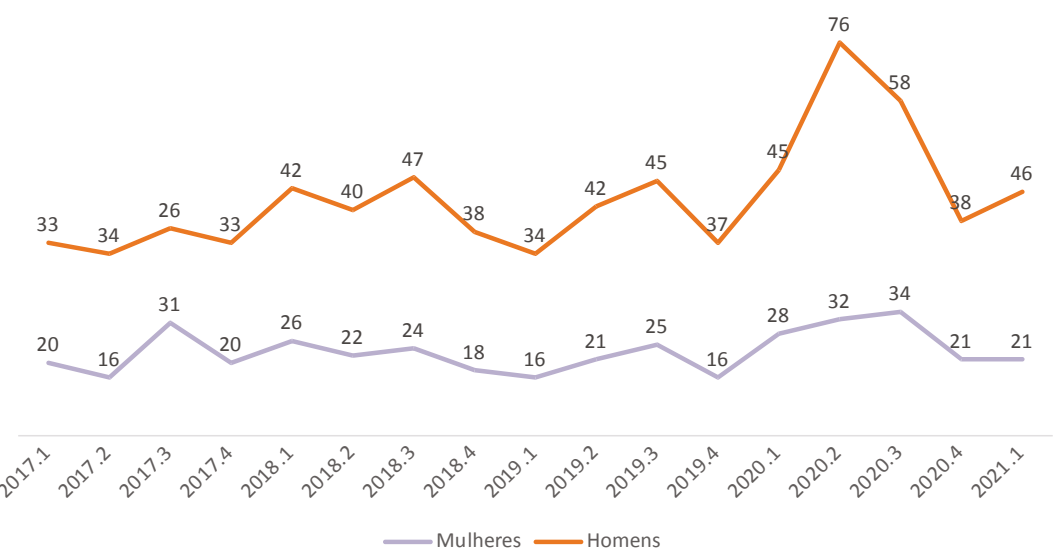

Fonte: ScholarOne. Elaboração própria.

Em 14 de maio de 2020, cerca de dois meses após a Organização Mundial da Saúde (OMS) decretar a pandemia de Covid-19, divulgamos no $B \log$ da DADOS resultados preliminares de queda de submissões de mulheres no começo da quarentena. Nossa análise, que abarcava uma parcela do segundo trimestre do ano (2020.2), mostrou que o gênero feminino liderava a autoria de apenas $13 \%$ dos artigos (Candido; Campos, 2020) - um percentual bastante preocupante em comparação às médias usuais da revista. Como o Gráfico 8 mostra, as mulheres recuperaram sua proporção de participação no restante do trimestre e fecharam o período liderando $30 \%$ das autorias. Ainda assim, trata-se do menor patamar entre 2017 e o primeiro trimestre de 2021, só comparável ao quarto trimestre de 2019. Nesse quesito, vale pontuar que, após a publicação do texto sobre a temática em nosso site, ocorreu um incremento dos envios de manuscritos assinados por elas. Não é possível determinar se uma coisa foi consequência da outra, mas temos tentado estimular o debate sobre diversidade e a submissão de autoras no periódico. 
Gráfico 8: Percentual de submissões com autoria de liderança feminina por trimestre (2017-2020)

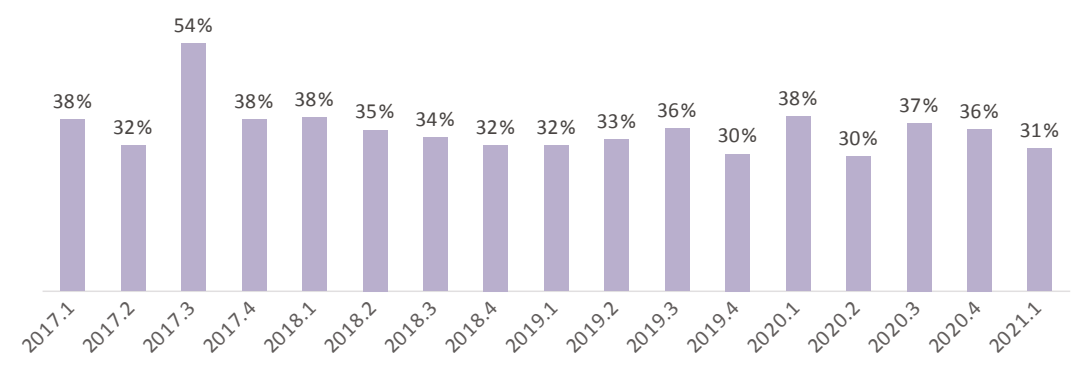

Fonte: ScholarOne. Elaboração própria.

No Gráfico 9, que trata do total de autores sem considerar a ordem de autoria, a desigualdade entre homens e mulheres permanece, ainda que de modo menos intenso. Tomando apenas o gênero da liderança da autoria, a razão média entre homens e mulheres é de 1,76. Já tomando a quantidade geral de homens e mulheres assinando um artigo, desconsiderada a ordem, essa razão cai para 1,45. Esse dado é importante porque a ordem das autorias pode servir como indício da divisão interna do trabalho acadêmico de acordo com os gêneros, dentro da qual a participação de mulheres não é necessariamente sinônimo de igualdade completa.

Gráfico 9: Quantidade geral de autores(as) por gênero e trimestre sem considerar a ordem (2017-2020)

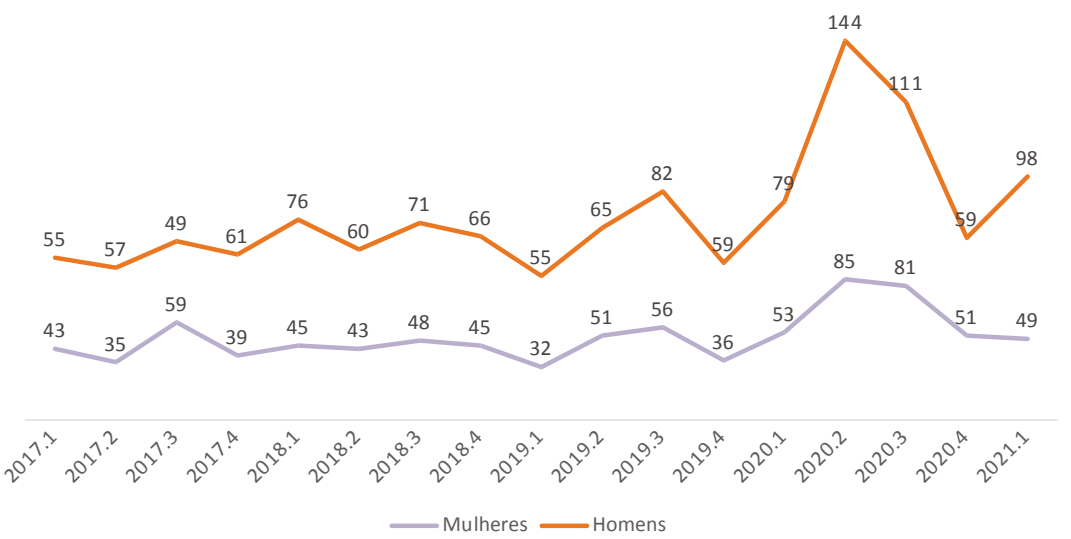

Fonte: ScholarOne. Elaboração própria. 
A comparação entre a proporção de mulheres liderando a autoria (Gráfico 8) e a proporção geral de mulheres autoras (Gráfico 10) ao longo dos anos atesta que quase sempre o gênero feminino está melhor representado em parcerias de pesquisa - e não em sua coordenação. Apenas no primeiro trimestre de 2018 os dados indicaram uma vantagem de $1 \%$ das mulheres em posição de liderança. É bom considerar, contudo, que algumas submissões organizam a autoria por ordem alfabética.

Gráfico 10: Percentual de mulheres na autoria dos textos por trimestre

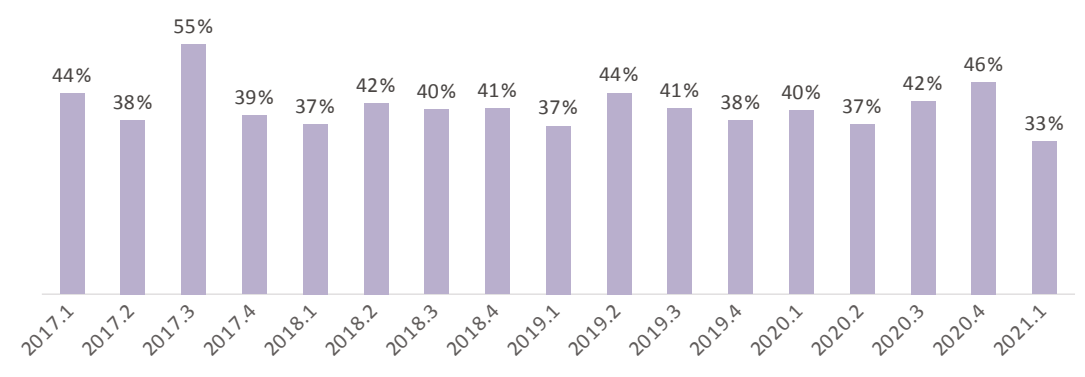

Fonte: ScholarOne. Elaboração própria.

Ainda no que diz respeito à diversidade de gênero, $D A D O S$ vem tentando promover paridade nas indicações de pareceristas. Para o ano de 2020, quase atingimos o intento, tendo fechado os percentuais em $42 \%$ de pareceristas mulheres e $58 \%$ de homens.

Gênero, todavia, não é a única categoria pertinente para discutir desigualdades na produção do conhecimento. Poderíamos abordar, por exemplo, determinantes de raça, classe e orientação sexual, mas essas informações ainda não estão acessíveis. ${ }^{5}$ DADOS utiliza como sistema de gestão de seus manuscritos a plataforma ScholarOne, que possibilita a extração de algumas características dos artigos, como o nome de seus autores ou as instituições às quais declaram vínculo.

A Tabela 2 apresenta a procedência nacional dos(as) pesquisadores(as) entre 2018 e 2020, quantificada com base no local sede de suas respectivas instituições. Os resultados para os últimos anos reforçam tendências já explicitadas em editoriais passados (Bringel, 2016), que 
destacam o português e o espanhol como idiomas elegidos nos manuscritos enviados à revista. A pandemia, iniciada em 2020, não chegou a impactar substantivamente esses números.

Tabela 2: Artigos submetidos por país de origem (2018-2020)

\begin{tabular}{|c|c|c|c|c|}
\hline País & 2018 & 2019 & 2020 & Total \\
\hline Brasil & 162 & 160 & 233 & 555 \\
\hline Espanha & 33 & 18 & 29 & 80 \\
\hline Chile & 17 & 18 & 13 & 48 \\
\hline Colômbia & 22 & 17 & 9 & 48 \\
\hline Portugal & 11 & 12 & 15 & 38 \\
\hline México & 5 & 6 & 6 & 17 \\
\hline Equador & 3 & 1 & 3 & 7 \\
\hline Argentina & 2 & 3 & 3 & 8 \\
\hline Turquia & - & 3 & 4 & 7 \\
\hline Rússia & 2 & 2 & - & 4 \\
\hline EUA & 1 & - & 1 & 2 \\
\hline China & 2 & - & - & 2 \\
\hline Indonésia & & 1 & 2 & 3 \\
\hline Polônia & 1 & - & 2 & 3 \\
\hline França & - & 1 & 1 & 2 \\
\hline Grécia & - & - & 2 & 2 \\
\hline Iraque & - & - & 2 & 2 \\
\hline Paquistão & 1 & - & 1 & 2 \\
\hline $\begin{array}{l}\text { Reino } \\
\text { Unido }\end{array}$ & 1 & 1 & - & 2 \\
\hline Uruguai & - & 1 & 1 & 2 \\
\hline Outros* & - & 3 & 9 & 12 \\
\hline
\end{tabular}

Fonte: ScholarOne. Elaboração própria.

*Outros: Angola, Azerbaijão, Chipre, Hong Kong, Japão, Jordânia, Nigéria, Peru, România, Arábia Saudita, Suécia, Vietnã e Zimbábue

Dentre os artigos recebidos de países estrangeiros, todavia, é bastante comum que o conteúdo se restrinja a estudos de caso de pequenos grupos locais ou regiões específicas, fugindo ao escopo editorial de 
$D A D O S$. É frequente, ademais, que os manuscritos sejam enviados sem corresponder às demais normas obrigatórias da revista - algo que também ocorre em pesquisas submetidas por brasileiros. Apesar disso, $46 \%$ dos textos publicados em 2020 foram veiculados em outros idiomas, em consonância com as recomendações da Rede SciELO. Do total de 13 casos, 3 foram também divulgados em teor bilíngue e traduzidos com recursos do auxílio editorial oriundo do Conselho Nacional de Desenvolvimento Científico e Tecnológico (CNPq).

\section{PÓS-PUBLICAÇÃO}

Outra frente constante de atuação da nossa editoria é o monitoramento de nossas métricas de citação. É verdade que tais métricas vêm sofrendo críticas cada vez mais incisivas, seja porque são calculadas a partir de bases de dados restritas a poucos países já dominantes na geopolítica científica global (Martinovich, 2020), seja porque suas fórmulas de cálculo expressam concepções de impacto acadêmico sempre discutíveis (Hicks et al., 2015). Logo, não as tomamos como indicadores absolutos da qualidade de nossos artigos, mas como indícios de eventuais potenciais ou limitações do nosso trabalho editorial. A tabela a seguir apresenta o desempenho comparado de algumas delas nos últimos dois anos.

Tabela 4: Métricas de impacto de DADOS

\begin{tabular}{lcc}
\hline Métrica de impacto & 2019 & 2020 \\
\hline Fator de impacto (Web of Science, Clarivate) & 0,288 & 0,357 \\
H5 (Google Scholar) & 17 & 17 \\
CiteScore (Scopus) & 0,5 & 0,6 \\
SJR (Scimago) & 0,240 & 0,211 \\
SNIP (CWTS) & 0,76 & 0,86 \\
\hline
\end{tabular}

Fonte: Elaboração própria a partir das bases de cada indexador.

De modo geral, as métricas de DADOS apresentam grande estabilidade. Tivemos uma evolução importante no Fator de Impacto da Web of Science (Clarivate) e do CiteScore da Scopus - duas bases focadas nas citações internacionais, sobretudo de artigos em inglês. Esses dois índices possuem formas de cálculo similares, que consideram a razão entre números de citações recebidas dentro de sua coleção e a quantidade de artigos publicados pela revista, variando em grande medida 
pelo tamanho de suas bases e o período de tempo considerado. $\mathrm{O}$ h5, do Google Scholar, que considera o número de artigos da revista que recebeu o mesmo número de citações nos últimos cinco anos, permaneceu estável em 17, junto com grande parte dos periódicos brasileiros das Ciências Sociais no mesmo período. ${ }^{6}$ Apenas o SJR da Scimago detectou queda de 0,240 para 0,211 . Isso pode ter ocorrido porque essa métrica é impactada pela definição da área temática da revista, classificada genericamente como de Ciências Humanas pela Scimago. Por fim, o Source Normalized Impact per Paper (SNIP), que pondera o cálculo do impacto conforme o número total de citações de um campo temático, também teve uma melhora. ${ }^{7}$

Em convergência com o plano de abertura da ciência, investimos na pluralização dos mecanismos de divulgação científica. O periódico aderiu a quase todos os principais canais virtuais existentes para circular os textos e as iniciativas de debate que promove. A Tabela 3 elenca a audiência consolidada em cada uma dessas redes, que almejam potencializar o impacto dos artigos e alcançar distintas gerações de acadêmicos(as).

Tabela 3: Divulgação científica de DADOS

\begin{tabular}{ll}
\hline Meios de divulgação & Audiência \\
\hline Site e Blog & Cerca de 12.000 visitas por mês \\
Facebook & 4.563 seguidores \\
Twitter & 3.169 seguidores \\
Instagram & 1.552 seguidores \\
Mailchimp & 1.505 assinantes \\
Podcast & 795 acessos aos episódios \\
Vídeos no YouTube & 1.563 visualizações \\
\hline
\end{tabular}

Fonte: Elaboração própria a partir das bases das redes sociais..

Combinados aos efeitos da pandemia da COVID-19 na digitalização da vida acadêmica, esses investimentos se refletiram no aumento significativo de nosso impacto nas redes sociais. Isso se expressa na quantidade de menções aos artigos de DADOS capturadas pelo site altmetric.com, especialmente no Twitter. Como indica o Gráfico 11, as menções à revista nessa rede já cresciam em 2019, mas bateram recordes sucessivos nos últimos três trimestres de 2020, período que coincide com o pico da pandemia. 
Gráfico 11: Menções a artigos de $D A D O S$ capturadas pelo site altmetric.com

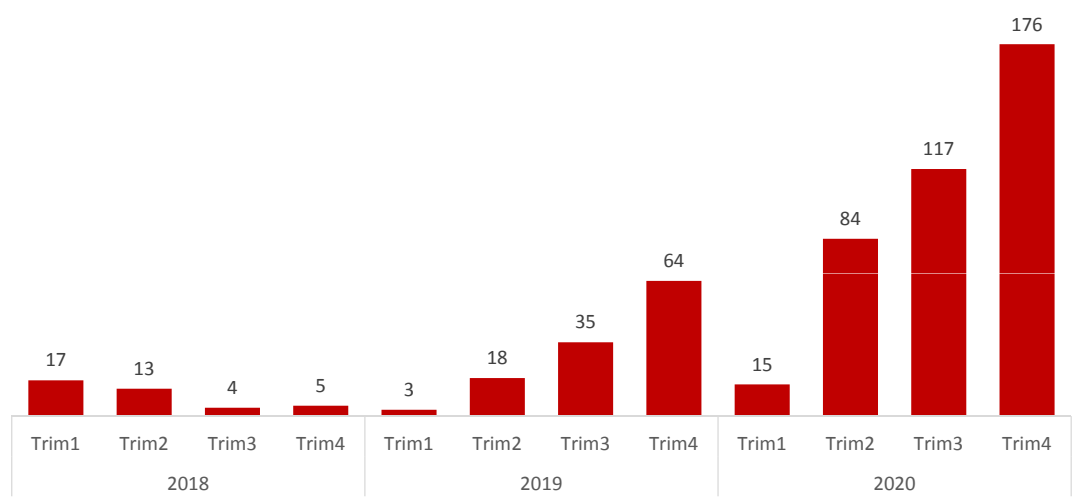

Fonte: Altmetrics. Elaboração própria.

Em consonância com a transparência de seus processos metodológicos, a revista passou a aceitar manuscritos disponibilizados em servidores preprints e a demandar o envio das bases de dados e algoritmos que originaram as análises dos artigos submetidos. Enquanto os preprints foram criados com o intuito de acelerar a disponibilização de dados de pesquisas em virtude da lentidão das diversas etapas que envolvem a publicação de um trabalho, o requerimento das bases de dados tem como propósito proporcionar a validação dos resultados apresentados nos textos frente aos pares.

Em estudo divulgado no número 3 do volume 64 da revista, George Avelino, Scott Desposato e Ivan Mardegan (2021) analisaram artigos de Ciência Política nas publicações brasileiras e demonstraram que a transparência e a possibilidade de replicação dos dados ainda constituem uma severa limitação da produção nacional. A implementação de tal regra em $D A D O S$ pretende, portanto, colaborar para reverter esse problema. Por outro lado, aumentamos a abrangência dos tipos de submissão que aceitamos com o mesmo objetivo. O periódico vai passar a receber neste ano comentários críticos e notas de investigações em curso. Ambas as frentes permitem enriquecer e amadurecer os debates sobre projetos de pesquisa. 


\section{CONSIDERAÇÕES FINAIS}

O objetivo deste texto foi fornecer informações acerca das submissões em $D A D O S$ e situar a revista em meio à conjuntura adversa que a ciência brasileira vem enfrentando há alguns anos. Destacamos números sobre o fluxo editorial, a diversidade de perfis sociais dos autores e pareceristas, e as ações de divulgação científica empregadas recentemente pela equipe da publicação. Os dados mostraram alguns dos desafios persistentes da editoria científica, que envolvem administrar um intenso fluxo de manuscritos e ainda lidar com as dificuldades de financiamento que ameaçam não só os periódicos, mas as universidades como um todo. Somado a isso, consideramos que o combate às desigualdades na ciência e a busca pelo aumento do seu impacto dentro e fora do mundo acadêmico são também pontos essenciais de constante trabalho.

Fizemos importantes avanços, sobretudo na redução do tempo médio de espera das avaliações, no monitoramento das desigualdades de gênero em nosso fluxo e na expansão de nossas redes de divulgação científica. No entanto, muitos desafios ainda restam, como aumentar a atenção às desigualdades raciais, sobre as quais temos poucos dados, e avançar paulatinamente nas práticas de ciência aberta. Todos esses desafios, é claro, estão condicionados pelas dificuldades de financiamento da revista, que permanecem não apenas para $D A D O S$, mas para a ciência brasileira em geral. De todo modo, seguimos com os esforços para que os cientistas sociais brasileiros e internacionais encontrem em nossas páginas uma das melhores opções de leitura e de circulação de suas pesquisas.

\section{NOTAS}

1. Como um manuscrito não aceito para a publicação pode ser reapresentado ou ressubmetido, muitos manuscritos podem ter mais de uma decisão editorial.

2. DADOS preparou uma breve miniaula sobre esse tema, publicada no Blog da DADOS e traduzida para publicação no blog SciELO Perspectiva (Campos, 2021a; 2021b).

3. Ver, dentre outros, Young (1995), Fernández (2006), Carpiuc (2016), Breuning e Sanders (2007), Evans e Moulder (2011), Williams et. al. (2015), Teele e Thelen (2017), Konig e Popers (2018), Campos, Feres e Guarnieri (2017), Samuels e Teele (2018), Mendes e Figueira (2019), Candido, Campos e Feres Júnior (2021).

4. O pacote do R que utilizamos como ponto de partida para a classificação foi o do pesquisador Fernando Meirelles. Disponível em: https:/ / fmeireles.com/blog/rstats / genderbr-predizer-sexo/ Acesso em 4 nov. 2021. 
Luiz Augusto Campos e Marcia Rangel Candido

5. DADOS incluiu recentemente no seu sistema de submissão uma questão sobre autodeclaração racial.

6. Em outras palavras, um h5 de 17 quer dizer que DADOS teve 17 artigos com 17 ou mais citações nos últimos cinco anos.

7. Mais informações sobre o significado desses índices podem ser acessadas em Auckland (2021).

8. Somatório de visualizações de dois vídeos promovidos por esta gestão de comunicação de DADOS. O primeiro se intitula "Desenho de Pesquisa e Redação Acadêmica" (Campos, 2020), e o segundo, “O que são preprints?" (Campos, 2021c). 


\section{REFERÊNCIAS}

AUCKLAND University of Technology. (2021), "Research Impact". Auckland University of Technology . 1 set. 2021 [Acessado em 1 de jun. 2021]. Disponível em https:/ /aut.ac.nz. libguides.com/impact.

AVELINO, George; DESPOSATO, Scott; MARDEGAN, Ivan. (2021), "Transparency and Replication in Brazilian Political Science: A First Look". DADOS, vol. 64, n. 3, pp. 1-49.

BOHLIN, Ingemar. (2004), "Communication Regimes in Competition: The Current Transition in Scholarly Communication Seen Through the Lens of the Sociology of Technology". Social Studies of Science, vol. 34, n. 3, pp. 365-91.

BORNMANN, Lutz. (2011), "Scientific Peer Review". Annual Review of Information Science and Technology, vol. 45, n. 1, pp. 197-245.

BORNMANN, Lutz; DANIEL, Hans-Dieter. (2010), “The Manuscript Reviewing Process: Empirical Research on Review Requests, Review Sequences, and Decision Rules in Peer Review". Library E Information Science Research, vol. 32, n. 1, pp. 5-12.

BRINGEL, Breno. (2016), "Nota editorial: política e fluxo editorial da DADOS. DADOS, vol. 59 , n. 2, pp. 311-321.

BROWN, Nadia; HORIUCHI, Yusaku; HTUN, Mala; SAMUELS, David (2019), “Gender gaps in perceptions of Political Science Journals". Political Science and Politics, vol. 40, n. 1, pp. 114-121.

BREUNING, Marijke; SANDERS, Kathryn. (2007), "Gender and Journal Authorship in Eight Prestigious Political Science Journals". PS: Political Science and Politics, vol. 40, n. 2, pp. 347-351.

CAMPOS, Luiz Augusto. (2019), "Como redigir um parecer acadêmico?". Blog da DADOS. 4 jul. 2019 [Acessado em 25 de ago. 2021]. Disponível em http://dados.iesp.uerj.br/ como-redigir-um-parecer/

CAMPOS, Luiz Augusto. (2020), "Desenho de Pesquisa e Redação Acadêmica, Aula 1: Qual o seu problema (de pesquisa)?". YouTube . 10 jun. 2020 [Acessado em 7 de jun. 2021]. Disponível em https:/ / www.youtube.com/watch?v=KckgtIjN3WQ

CAMPOS, Luiz Augusto. (2021a), “O que são preprints?”. Blog da DADOS . 10 maio 2021 [Acessado em 24 de jun. 2021]. Disponível em http://dados.iesp.uerj.br/o-que-sao-preprints /

(2021b), "What are preprints?". SciELO in Perspective . 2 jun. 2021 [Acessado em 24 jun. 2021]. Disponível em https://blog.scielo.org/en/2021/06/02/what-are-preprints-originally-published-in-dados-blog-in-may-2021/

CAMPOS, Luiz Augusto. (2021c), “DADOS - O que são preprints?”. YouTube. 10 maio 2021 [Acessado em 7 jun. 2021]. Disponível em https://www.youtube.com/ watch?v=G1oWyQOP1JQ

CAMPOS, Luiz Augusto; FERES JÚNIOR, João; GUARNIERI, Fernando. (2017), 50 Anos da Revista DADOS: Uma Análise Bibliométrica do seu Perfil Disciplinar e Temático. DADOS, vol. 60, n. 3, pp. 623-661. 
CANDIDO, Marcia; CAMPOS, Luiz Augusto. (2020), "Pandemia reduz submissão de mulheres". Blog da DADOS. 14 maio 2020 [Acessado em 5 de jun. 2021]. Disponível em http://dados.iesp.uerj.br/pandemia-reduz-submissoes-de-mulheres/

CANDIDO, Marcia; CAMPOS, Luiz Augusto; FERES JUNIOR, Joao. (2021), “The Gendered Division of Labor in Brazilian Political Science Journals". Brazilian Political Science Review, vol. 15, no. 3 .

CANDIDO, Marcia; MARQUES, Danusa; ELIAS, Vanessa; BIROLI, Flávia. (2021), “As Ciências Sociais na pandemia da Covid-19: rotinas de trabalho e desigualdades". Sociologia e Antropologia, vol.11, no. especial.

CANDIDO, Marcia; FERES JUNIOR, João; CAMPOS, Luiz Augusto. (2019), “Desigualdades na elite da ciência política brasileira". Civitas, vol. 19, no. 3, pp. 564-582.

CARPIUC, Cecilia. (2016), "Women and Diversity in Latin American Political Science". European Political Science, vol. 15, no. 4, pp. 457-475.

CASTRO, Bárbara; CHAGURI, Mariana. (2020), “Um tempo só para si: gênero, pandemia e uma política científica feminista". Blog da DADOS. 22 maio 2020 [Acessado em 5 jun. 2021]. Disponível em http://dados.iesp.uerj.br/pandemia-cientifica-feminista/

CUI, Ruomeng; DING, Hao; ZHU, Feng. (2020), "Gender Inequality in Research Productivity During the Covid-19 Pandemic". Social Science Research Network. 9 jun. 2020 [Acessado em 2 de set. 2020]. Disponível em http://dx.doi.org/10.2139/ssrn.3623492

DJUPE, P. A.; SMITH, A. E.; SOKHEY, A. E. (2019), "Explaining Gender in the Journals: How Submission Practices Affect Publication Patterns in Political Science". Political Science \& Politics, vol. 52, no. 1, pp. 71-77.

EBERLEY, Susan; WARNER, W. Keith. (1990), "Fields or Subfields of Knowledge: Rejection Rates and Agreement in Peer Review". The American Sociologist, vol. 21, no. 3, pp. 217-231.

ELSE, Holly. (2020), "How a Torrent of COVID Science Changed Research Publishing - in Seven Charts". Nature. 2020, vol. 588, p. 533. [Acessado em 24 jun. 2021]. Disponível em https://doi.org/10.1038/d41586-020-03564-y

EVANS, Heather; MOULDER, Ashley. (2011), "Reflecting on a Decade of Women's Publications in Four Top Political Science Journals". PS: Political Science and Politics, vol. 44, no. 4, pp. 793-798.

FERES JUNIOR, João. (2020), “Ensino e pesquisa em ciências sociais no Brasil: um retrato das desigualdades de gênero e raça", in F. Biroli, L. Tatagina, C. Almeida, C. Buarque de Hollanda e V. Elias de Oliviera (orgs.), Mulheres, poder e ciência política: debates e trajetórias. São Paulo, Editora Unicamp, pp. 167-194.

FERNANDEZ, Maria. (2006), "Mujer y ciencia política en Chile: ¿algo nuevo bajo el sol?*”. Politica, vol. 46, pp. 261-289.

HARGENS, Lowell L. (1988), "Scholarly Consensus and Journal Rejection Rates". American Sociological Review, vol. 53, no. 1, pp. 139-51.

HARGENS, Lowell L; HERTING, Jerald R. (1990), “A New Approach to Referees' Assessments of Manuscripts". Social Science Research, vol. 19, no. 1, pp. 1-16. 
HICKS, Diana; WOUTERS, Paul; WALTMAN, Ludo; RIJCKE, Sarah; RAFOLS, Ismael. (2015), "Bibliometrics: The Leiden Manifesto for research metrics". Nature, 2015, vol. 520, no. 7548, pp. 429-431 [Acessado em 25 ago. 2021]. Disponível em https://doi. org $/ 10.1038 / 520429$ a

KONIG, Thomas; ROPERS, Guido. (2018), "Gender and Editorial Outcomes at the American Political Science Review". PS: Political Science \& Politics, vol. 51, n. 4, pp. 849-853.

MARTINOVICH, Viviana (2020), “Indicadores de citação e relevância científica: genealogia de uma representação". Dados, 2020, vol. 63, n. 2 [25-08-2021] e20190094. Disponível em https://doi.org/10.1590/001152582020218

MENDES, Marcos; FIGUEIRA, Ariane. (2019), “Women's Scientific Participation in Political Science and International Relations in Brazil". Revista de Estudos Feministas, vol. 27, n. 2, pp. 1-13.

SAMUELS, David; TEELE, Dawn. (2018), “New medium, same story: gender gaps in book publishing". Political Science \& Politics, vol. 54, n. 1, pp. 131-140.

SOARES, Gláucio Ary Dillon. (2005), “O calcanhar metodológico da Ciência Política no Brasil”. Sociologia, Problemas e Práticas, n. 48, pp. 27-52.

STANISCUASKI, Fernanda et al. (2021), "Gender, Race and Parenthood Impact Academic Productivity During the Covid-19 Pandemic: From Survey to Action". Frontiers in Psychology, vol. 12.

TEELE, Dawn; THELEN, Kathleen. (2017), "Gender in the Journals: Publication Patterns in Political Science". PS: Political Science \& Politics, vol. 50, n. 2, pp. 433-447.

WELLER, Ann. (2001), Editorial Peer Review: Its Strengths and Weaknesses. Information Today, Inc.

WILLIAMS, Helen; BATES, Stephen; JENKINS, Laura; LUKE, Darcy; ROGERS, Kelly. (2015), "Gender and Journal Authorship: An Assessment of Articles Published by Women in Three Top British Political Science and International Relations Journals". European Political Science, vol. 14, n. 2, pp. 116-130.

YOUNG, Cheryl. (1995), "An Assessment of Articles Published by Women in 15 Top Political Science Journals". PS: Political Science and Politics, v. 28, n. 3, p. 525-533.

ZUCKERMAN, Harriet; MERTON, Robert. (1971), “Patterns of Evaluation in Science: Institutionalisation, Structure and Functions of the Referee System". Minerva, vol. 9, n. 1, pp. 66-100. 


\section{RESUMO}

Transparência em DADOS: submissões, pareceristas e diversidade no fluxo editorial dos últimos anos

Este editorial discute dados gerais sobre o fluxo dos manuscritos submetidos na revista $D A D O S$, bem como os desafios que a publicação enfrentou nos últimos anos. Apresentamos aqui uma análise cienciométrica de diversas dimensões do nosso trabalho, desde as submissões recebidas até o perfil de seus pareceres e pareceristas, passando pelas persistentes desigualdades de gênero e de origem geográfica nesses âmbitos e pelas diferentes métricas de impacto da revista. Pretendemos assim garantir a mais ampla transparência de nossos processos editoriais, sem prejudicar, contudo, os critérios de discrição que embasam o sistema de revisão anônima por pares. Ademais, pretendemos compartilhar as estratégias que utilizamos para contornar os obstáculos interpostos à editoria científica brasileira, com a expectativa de que elas possam servir como instrumentos de resistência às crises sucessivas enfrentadas por outros periódicos científicos nacionais e internacionais.

Palavras-chave: ciência; editoria científica; revisão por pares; citações; diversidade de gênero

\section{ABSTRACT \\ Transparency in DADOS: submissions, reviewers, and editorial workflow diversity in recent years}

This editorial discusses general data concerning the manuscripts workflow of $D A D O S$, and the challenges faced by the journal in the last few years. It presents a scientometric analysis of several dimensions of the periodical's workflow, ranging from submissions to the profile of reviews and reviewers also addressing persisting gender and spatial inequalities and the journal's different impact metrics. The work aims to ensure greater transparency in editorial processes without losing sight of the discretion criteria that underly our anonymous peer-review system. Besides, our goal is to share the strategies employed to overcome obstacles faced by science communication in Brazil in the hope that they may work as instruments of resistance against the many and recurring crises faced by other national and international scientific journals.

Keywords: science; scientific publishing; peer reviews; citations; gender diversity 


\section{RÉSUMÉ}

Transparence à la revue DADOS: soumissions, révision et diversité au processus éditorial des dernières années

Cet éditorial présente des données générales concernant le flux de manuscrits soumis à $D A D O S$ et les défis de la publication ces dernières années. Nous présentons une analyse scientométrique de plusieurs dimensions du travail éditorial, depuis les soumissions reçues jusqu'au profil de ses référées, en passant par les inégalités de genre et d'origine géographique et les différentes métriques d'impact de la revue. Nous entendons ainsi assurer la plus grande transparence de nos processus éditorial, sans préjuger la discrétion propre du système d'évaluation anonyme. En outre, nous avons l'intention de partager les stratégies que nous avons utilisées pour surmonter les obstacles à la publication scientifique brésilienne, dans l'espoir qu'elles puissent servir d'instruments de résistance aux crises successives auxquelles sont confrontées d'autres revues scientifiques nationales et internationales.

Mots clés: science; publication scientifique; révision scientifique; citations; diversité sexuelle

\section{RESUMEN}

Transparencia en DADOS: envíos, evaluadores y diversidad en el flujo editorial de los últimos años

Este editorial presenta y discute datos generales sobre el flujo de los manuscritos enviados a la revista $D A D O S$, así como los desafíos que la publicación enfrentó en los últimos años. Aquí presentamos un análisis de cienciometría sobre distintas dimensiones de nuestro trabajo, desde los envíos recibidos hasta el perfil de las evaluaciones y los evaluadores, pasando por las persistentes desigualdades de género y de origen geográfico en esos ámbitos y por las diferentes métricas de impacto de la revista. Pretendemos, de esta forma, garantizar la más amplia transparencia de nuestros procesos editoriales, sin perjudicar, no obstante, los criterios de discreción que sostienen el sistema de revisión anónima por pares. Además, pretendemos compartir las estrategias que utilizamos para responder a los obstáculos interpuestos a la edición científica brasilera, con la expectativa de que puedan servir como instrumentos de resistencia a las crisis sucesivas enfrentadas por otros periódicos científicos nacionales e internacionales.

Palabras clave: ciencia; edición científica; revisión por pares; citaciones; diversidad de género 